\title{
Upper bounds on subglacial channel development for interior regions of the Greenland ice sheet
}

\author{
C.F. DOW, ${ }^{1 *}$ B. KULESSA, ${ }^{1}$ I.C. RUTT, ${ }^{1}$ S.H. DOYLE, ${ }^{2}$ A. HUBBARD ${ }^{2}$ \\ ${ }^{1}$ Glaciology Group, College of Science, Swansea University, Swansea, UK \\ E-mail: christine.f.dow@nasa.gov \\ ${ }^{2}$ Centre for Glaciology, Department of Geography and Earth Sciences, Aberystwyth University, Aberystwyth, UK
}

\begin{abstract}
We use a simple numerical model to test whether surface water influx to the bed of the interior Greenland ice sheet has the potential to cause significant subglacial channel growth similar to that observed near the ice-sheet margin and at alpine glaciers. We examine the effects on channel growth from (1) rapid supraglacial lake drainage events and (2) sustained water input into moulins. By assuming that all drainage occurs through subglacial channels and by prescribing favorable pressure conditions at the domain inlet, the model can provide upper bounds on channel growth. Our results indicate that R-channels do not grow significantly within the limited period of high pressure associated with lake drainage events. Subsequent channel growth only occurs with sustained pressures above overburden. Rapid closure of channels at low pressures suggests channels in the interior are unlikely to draw significant quantities of water from nearby distributed networks. These results indicate that other drainage mechanisms such as turbulent sheets or linked-cavity networks are likely to be of greater importance for interior subglacial drainage than the growth of channels.
\end{abstract}

KEYWORDS: Arctic glaciology, glacier hydrology, glacier modelling, ice-sheet modelling, subglacial processes

\section{INTRODUCTION}

Efficient subglacial drainage networks consisting of arborescent systems of channels, akin to those beneath alpine glaciers, have been postulated to develop under Greenland outlet glaciers during the summer melt season (Shepherd and others, 2009; Bartholomew and others, 2010, 2012; Cowton and others, 2013; Sole and others, 2013). These Röthlisberger channels (R-channels), which are formed by melting of the overlying ice by turbulent water flow (Röthlisberger, 1972), are argued to reduce summer ice velocity below the winter average by drawing water from the surrounding distributed drainage system, resulting in less basal lubrication (Nienow and others, 1998; Bartholomew and others, 2011; Shannon and others, 2013; Sole and others, 2013).

Rapid supraglacial lake drainage events have been suggested as a cause of significant subglacial channel growth under the Greenland ice sheet (GrIS) (Das and others, 2008; Hoffman and others, 2011; Pimentel and Flowers, 2011; Cowton and others, 2013). These rapid drainage events evacuate millions of cubic meters of water from the ice surface to the bed in a matter of hours (Das and others, 2008; Doyle and others, 2013). GPS receivers in the vicinity of lake drainage events have recorded ice surface uplift in the initial stages of drainage, followed by subsidence within 24 hours (Das and others, 2008; Hoffman and others, 2011; Doyle and others, 2013; Tedesco and others, 2013). This subsidence has been attributed to the presence of subglacial channels that efficiently remove the large volumes of lake water from the region (Das and others, 2008; Hoffman and others, 2011; Pimentel and Flowers, 2011).

Surface meltwater also reaches the ice-sheet bed through moulins, either directly (Catania and others, 2008) or via the

*Present address: Cryospheric Sciences Lab, NASA Goddard Space Flight Center, Greenbelt, MD, USA. overtopping of surface lakes (Banwell and others, 2013). Such moulin drainage is argued to have a greater dynamic impact over the summer melt season when compared with rapid lake drainage events (Tedesco and others, 2013). Moulins in Greenland appear to be active over multiple years and are therefore argued to be likely to establish efficient drainage systems (Catania and Neumann, 2010).

We are interested in determining whether efficient channels can form in interior regions of the GrIS as a result of either rapid lake or moulin drainage. Our definition of 'interior' is based on a combination of shallow ice surface slopes, thick ice and a sufficient distance from the margin that drainage systems are unlikely to be connected to lowpressure outlets. One way to determine whether channels are a primary mechanism for large-scale subglacial drainage in the interior of the GrIS is to estimate the rates of growth and closure of these channels under various pressure-forcing scenarios. If channels are to be active in rapid lake drainage or summer melt drainage through moulins, they must be capable either of sufficiently rapid growth at the inception of drainage, or of being maintained over the winter. However, shallower surface slopes and thicker ice in the interior of the GrlS may restrict basal channel growth by preventing strong hydraulic potential gradients and enhancing creep closure, making these requirements difficult to fulfill (Chandler and others, 2013; Meierbachtol and others, 2013).

We apply an R-channel model to a region of thick, shallow surface-gradient ice to estimate a best-case scenario for channel growth during both lake drainage events and moulin drainage for the interior of the GrIS. We do not complicate our model by including linked-cavity drainage or turbulent sheets, which are likely to contribute to subglacial drainage (e.g. Flowers and Clarke, 2002; Hewitt, 2011; Pimentel and Flowers, 2011; Schoof and others, 2012; Kingslake and $\mathrm{Ng}, 2013$ ), but instead focus on the physics of channel growth alone and examine whether 


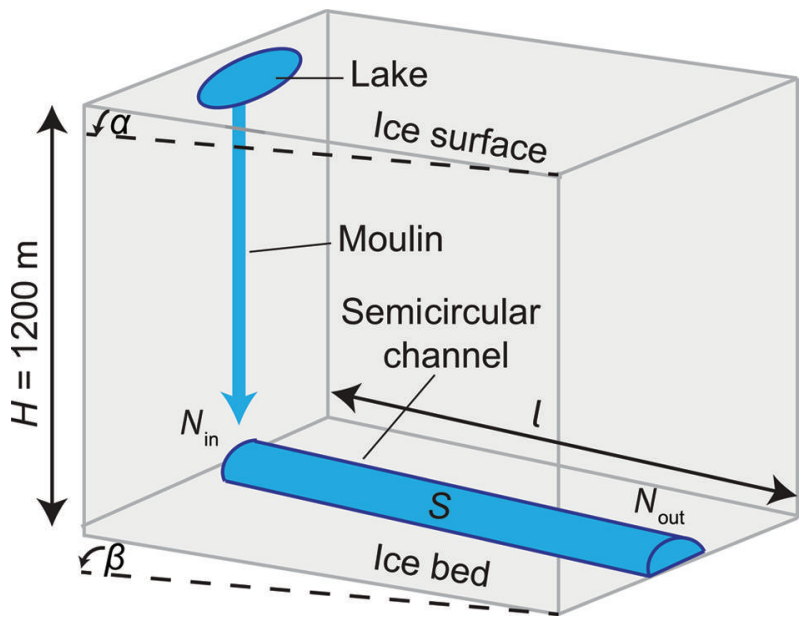

Fig. 1. Schematic of the R-channel model applied to a lake drainage overpressure scenario.

efficient channels can form when all drainage water is focused through this type of system. Our results are therefore an upper estimate of the channel growth that might be occurring in reality.

The equations to define R-channel growth were developed by Röthlisberger (1972) for a steady-state system and adapted by Nye (1976) to apply to spatially and temporally varying hydrological networks. We apply the Nye (1976) equations to a region with kilometer-thick interior ice to test: (1) whether subglacial channels can form during the shortlived but substantial water inputs associated with supraglacial lake drainage events; (2) how much basal channel development occurs from longer-term surface drainage into moulins; and (3) whether channels can persist with pressures below ice overburden.

\section{R-CHANNEL MODEL}

Nye (1976) developed a system of equations to describe Rchannel growth based on the competition between ice melting from turbulent dissipation of heat within the channel and closure of the channel due to the weight of the overlying ice, while conserving mass and momentum. These equations have been adapted for application to the GrlS by Schoof (2010), who used expressions for channel development alongside linked-cavity growth to examine hydrological development within $10 \mathrm{~km}$ of the ice-sheet margin. Chandler and others (2013) utilized the Schoof (2010) equations but omitted the cavity formation term and therefore focused only on channel growth. They examined channel growth up to $57 \mathrm{~km}$ from the ice margin, where ice thicknesses reach $1180 \mathrm{~m}$, to estimate the impact of constant water pressures on channel growth. Our approach is to examine instead the impact of variable water pressure on basal channel growth, including the effects of water pressures greater than the ice overburden pressure, for regions of interior Greenland ice. Our model produces upper bounds on channel growth by (1) assuming sufficient water supply is available to produce the water pressures that we impose on the upper domain of our channel and (2) forcing water through the channel rather than in linked cavities or in a turbulent sheet. This maximizes the potential for subglacial channel growth; consequently, if sufficient channel growth is not seen in the model, it is unlikely to be possible in reality.
Following Fowler (1999) we model the development of semicircular R-channels by restating the Nye (1976) equations in terms of the channel cross-sectional area, $S\left(\mathrm{~m}^{2}\right)$, and the effective pressure, $N=P_{\mathrm{i}}-P_{\mathrm{w}}$, where $P_{\mathrm{w}}$ is the water pressure and $P_{\mathrm{i}}=\rho_{\mathrm{i}} g\left(h_{\mathrm{a}}-h_{\mathrm{b}}\right)$ is the ice overburden pressure with $g=9.81 \mathrm{~m} \mathrm{~s}^{-2}$ the acceleration due to gravity, $\rho_{\mathrm{i}}=917 \mathrm{~kg} \mathrm{~m}^{-3}$ the density of ice, and $h_{\mathrm{a}}$ and $h_{\mathrm{b}}$ the elevations of the ice surface and ice bed, respectively. The temporal evolution of the channel cross-sectional area $S$ is

$$
\frac{\partial S}{\partial t}=\frac{m_{\mathrm{i}}}{\rho_{\mathrm{i}}}-\frac{2 A}{n^{n}} S N^{n},
$$

where $m_{\mathrm{i}}\left(\mathrm{m} \mathrm{s}^{-1}\right)$ is the melt rate of the channel walls. The second term on the right-hand side is related to the creep closure of ice, where parameters $A=1.6 \times 10^{-24} \mathrm{~s}^{-1} \mathrm{~Pa}^{-3}$ and $n=3$ from Glen's flow law control the ice softness. The melting condition through turbulent heat generation is given by

$$
m_{\mathrm{i}}=\frac{Q}{L}\left(\frac{\partial \psi}{\partial s}\right),
$$

where $L=3.35 \times 10^{5} \mathrm{~J} \mathrm{~kg}^{-1}$ is the latent heat of fusion, $Q$ $\left(\mathrm{m}^{3} \mathrm{~s}^{-1}\right)$ is the flux of water through the channel and $s(\mathrm{~m})$ is the along-flow coordinate. Following Shreve (1972), $\psi=\rho_{\mathrm{w}} g h_{\mathrm{b}}+P_{\mathrm{w}}$ is the hydraulic potential with $\rho_{\mathrm{w}}=1000$ $\mathrm{kg} \mathrm{m}^{-3}$ the density of water. The along-flow gradient of hydraulic potential is given by

$$
\frac{\partial \psi}{\partial s}=\left[\rho_{\mathrm{w}} g \frac{\partial h_{\mathrm{b}}}{\partial s}+\rho_{\mathrm{i}} g\left(\frac{\partial h_{\mathrm{a}}}{\partial s}-\frac{\partial h_{\mathrm{b}}}{\partial s}\right)\right]-\frac{\partial N}{\partial s}=\phi-\frac{\partial N}{\partial s} .
$$

The terms in the square brackets represent the geometric portion of the hydraulic potential gradient and are hereafter denoted as $\phi$. The effects of geothermal heating and water produced by frictional heating from sliding are ignored because they are likely insignificant compared with the turbulent dissipation of heat generated from the potential gradient (Alley and others, 2003). Using the GaucklerManning-Strickler formula for flow, $v\left(\mathrm{~m} \mathrm{~s}^{-1}\right)$, the crosssectional mean velocity along the channel, is

$$
v=\frac{R_{\mathrm{H}}^{\frac{2}{3}}}{n^{\prime}}\left(\frac{1}{\rho_{\mathrm{w}} g}\right)^{\frac{1}{2}}-\frac{\partial \psi}{\partial s}\left|\frac{\partial \psi}{\partial s}\right|^{-\frac{1}{2}}=\frac{Q}{S},
$$

where $R_{\mathrm{H}}$ is the hydraulic radius of a semicircular channel and $n^{\prime}=0.05 \mathrm{~s} \mathrm{~m}^{-\frac{1}{3}}$ is the Manning roughness coefficient representing a channel wall with medium roughness (Cuffey and Paterson, 2010). $Q$ is therefore given by

$$
Q=\left(\frac{S R_{\mathrm{H}}^{\frac{2}{3}}}{n^{\prime} \sqrt{\rho_{\mathrm{w}} g}}\right)-\frac{\partial \psi}{\partial s}\left|\frac{\partial \psi}{\partial s}\right|^{-\frac{1}{2}}
$$

Substituting Eqns (2) and (5) into Eqn (1) yields an equation for the time evolution of $S$ :

$$
\frac{\partial S}{\partial t}=\left(\frac{S(\pi \sqrt{(2 S / \pi)})^{\frac{2}{3}}}{n^{\prime} L \rho_{\mathrm{i}} \sqrt{\rho_{\mathrm{w}} g}(2 \pi+4)^{\frac{2}{3}}}\right)\left(-\frac{\partial \psi}{\partial s}\left|\frac{\partial \psi}{\partial S}\right|^{-\frac{1}{2}}\right)-\frac{2 A}{n^{n}} S N^{n} .
$$

\section{MODEL SET-UP}

A schematic of the model domain is shown in Figure 1. The geometry of the model domain is chosen to approximate the ice thickness and surface slope at a site $\sim 70 \mathrm{~km}$ from the GrIS ice margin in the catchment of Russell Glacier, West Greenland. The site was the location of a rapid supraglacial 
lake drainage in June 2010 (Doyle and others, 2013). The domain comprises a segment of channel with length I, with surface water input to the bed at the upstream channel boundary. This channel segment is assumed to be full at all times. The model is driven by changes in effective pressure at the water inlet, used as a proxy for the flux of water input into the surface-to-bed connection. During our lake drainage experiments the water pressure in the connecting moulin (and the upper channel boundary) is constrained by the lake level. For our diurnal moulin drainage experiments, we instead assume sufficient water is available to maintain the variable effective pressure in the moulin that we impose as a model upper boundary condition. The domain length, $I$, represents the region of the bed we assume is affected by the over- or under-pressure fluxes driven by the pressure in the water inlet; as this quantity is unknown, we test various channel segment lengths to assess the impact on channel growth. For all model runs, the basal and surface topographies are assumed to be planar, with bed $(\beta)$ and surface $(\alpha)$ angles of $0.20^{\circ}$ and $0.35^{\circ}$, respectively. The ice thickness, $H$, is $1200 \mathrm{~m}$ at the upstream end of the domain. The values for $\beta, \alpha$ and $H$ are averaged from surface and basal digital elevation models (DEMs) of the case study lake site (Lindbäck and others, 2014). Using these values, the geometric component of the hydraulic potential gradient, $\phi$, can be defined as $\phi=\rho_{\mathrm{w}} g \beta+\rho_{\mathrm{i}} g(\alpha-\beta)$. We assume a constant drop in effective pressure over the channel length segment and as a result $\partial N / \partial s$ can be approximated as $\left(N_{\text {out }}-N_{\text {in }}\right) / I$. These approximations can be used to simplify Eqn (6) to a time-dependent ordinary differential equation:

$$
\begin{aligned}
\frac{\mathrm{d} S}{\mathrm{~d} t}= & \left(\frac{S(\pi \sqrt{(2 S / \pi)})^{\frac{2}{3}}}{n^{\prime} L \rho_{\mathrm{i}} \sqrt{\rho_{\mathrm{w}} g}(2 \pi+4)^{\frac{2}{3}}}\right)\left[-\phi+\left(\frac{N_{\text {out }}-N_{\text {in }}}{l}\right)^{\frac{1}{2}}\right] \\
& -\frac{2 A}{n^{n}} S\left(\frac{N_{\text {in }}+N_{\text {out }}}{2}\right)^{n} .
\end{aligned}
$$

By driving channel growth with effective pressure at the inlet rather than an estimate of surface water volume input, we produce a maximum channel size; in reality, temporally variable water volume flowing through the channel will result in lower water pressures than assumed here and cause channel shrinkage. In addition, by assuming a planar topography we provide the best-case scenario for channel growth in this region; if we instead incorporated basal reverse slopes it would hinder channel growth.

In each experiment, we evolve $S$ using Eqn (7) with an initial condition of $S=0.01 \mathrm{~m}^{2}$ to represent an inefficient drainage system. The boundary condition at the domain outlet (Fig. 1) is assumed to be zero effective pressure $\left(N_{\text {out }}=0\right)$ for all experiments. This therefore represents a scenario where the outlet $P_{\mathrm{w}}$ is equal to the ice overburden pressure, a reasonable assumption under thick ice. It is this quality along with the shallow surface slope and thick ice that differentiates our study site from those nearer the margin (e.g. Das and others, 2008; Banwell and others, 2013; Tedesco and others, 2013). Closer to the drainage outlet it is likely that channel pressures would drop below overburden, creating a stronger hydraulic potential gradient and allowing greater channel growth. However, to estimate the distance from the margin at which this transition would occur requires a more sophisticated model. For our model approach, configured for interior ice, we vary the upper boundary condition, $N_{\text {in }}$, close to overburden pressure depending on the model test, as detailed below. All tests are run with a forward Euler method using a time step of 2 min, which allows for model convergence, so that the transient behavior of R-channel growth can be estimated.

\section{MODEL LIMITATIONS}

The model discussed in this paper is simplified and its purpose is not to estimate all the basal hydrological conditions of interior GrIS drainage systems. For example, lateral flow into and out of a channel from the surrounding region is not represented in the model. With pressures above overburden, hydraulic jacking will occur and water will be able to flow out into a sheet. However, as we attempt to constrain the upper bounds of channel growth it is interesting to determine the extent of channel development in extreme situations when water pressures are above overburden. This is particularly relevant for our application of this model, since the growth of channels during highly pressured lake drainage events has been suggested to allow evacuation of much of the water at the bed within a matter of hours (Das and others, 2008; Hoffman and others, 2011; Pimentel and Flowers, 2011).

The presence of a pressurized distributed system adjacent to the channelized system could provide water to the channels when pressures drop below overburden. However, as we drive the model with scenarios when channel pressures are at or very near overburden, we incorporate the possible flux of water from a distributed system into the channels by assuming that sufficient water is available to maintain the imposed pressure gradient. In order to better assess the role of channels versus a distributed system in hydrological development during lake drainage, a more complex coupled model is necessary (e.g. Flowers and Clarke, 2002; Hewitt, 2011; Pimentel and Flowers, 2011; Kingslake and $\mathrm{Ng}$, 2013). These models also incorporate variable channel growth along the domain, driven by changes in channel discharge. Our model lacks this variability and instead assumes uniform growth over the domain. Applying a more sophisticated model with coupled distributed and channelized drainage along with spatial variability to lake drainage events is an interesting area for future research.

As the channel pressure in our model is coupled directly with the depth of water in a moulin or supraglacial lake, the discharge required to cause that change of pressure in the inlet is not necessarily represented by the flux through the channel. This gives us the ability to put an upper bound on channel formation without having to link to a more complicated system coupled with the surface and/or a basal distributed system. For our purposes, driving channel growth with pressure alone is therefore sufficient.

The limitations in our approach likely lead to an overestimation in the channel growth in interior regions. As a result, it will be valuable for future work with more sophisticated coupled models to investigate the spatial and temporal variations in subglacial hydrology as a result of lake and moulin drainage.

\section{SUPRAGLACIAL LAKE DRAINAGE EXPERIMENTS}

We first apply the R-channel model to examine conduit growth during rapid lake drainage events in regions of kilometer-thick ice. Model input data are supplied from measurements of lake surface lowering during a rapid 

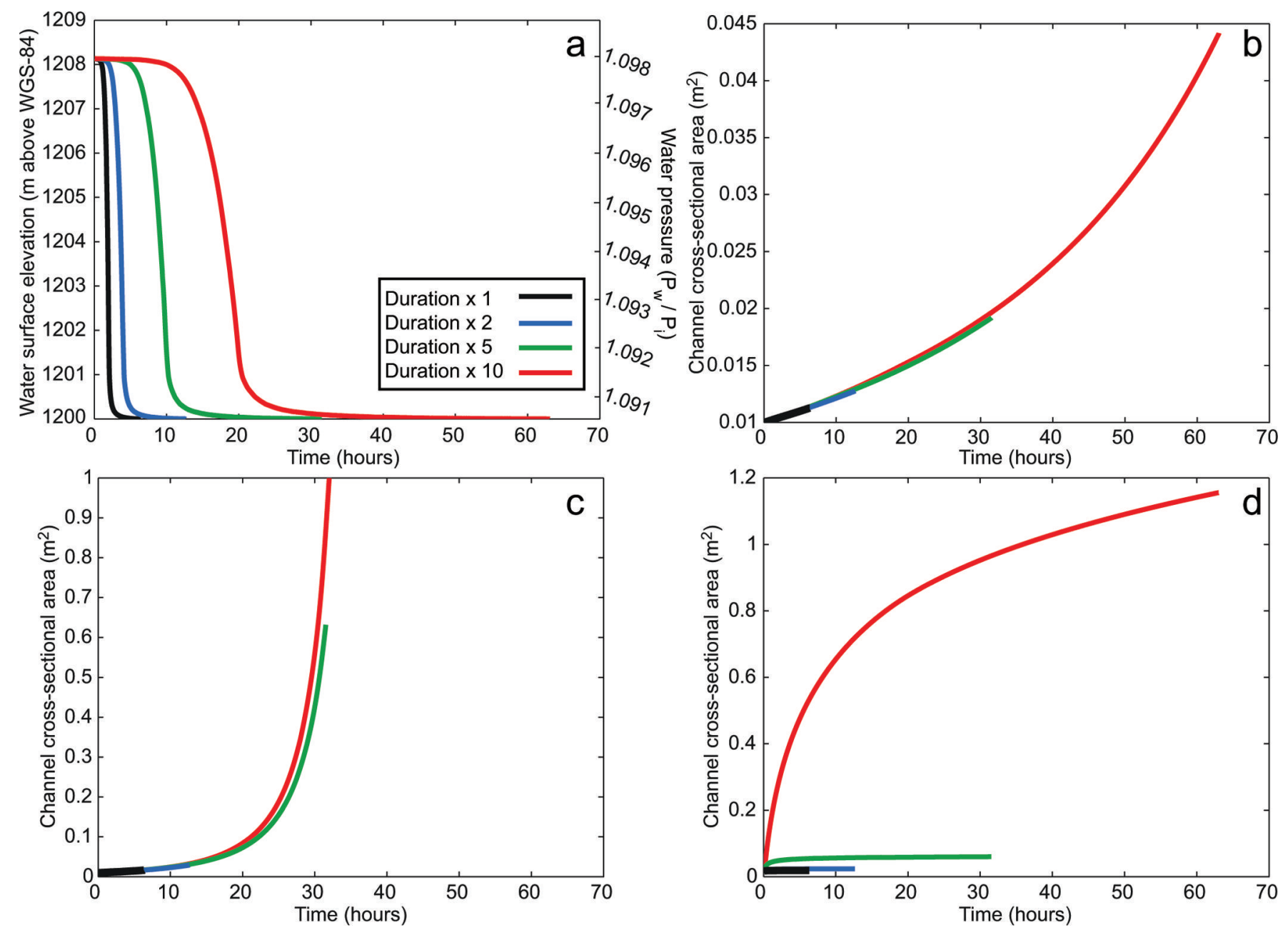

Fig. 2. R-channel model outputs testing the sensitivity of channel development to varying overpressure duration and segment length. (a) Lake surface elevation and water pressure in the surface-to-bed connection. (b) Channel cross-sectional area development over a static overpressurized segment length of $500 \mathrm{~m}$, for the lake drainage durations shown in (a). (c) Channel cross-sectional area development over a static overpressurized segment length of $200 \mathrm{~m}$. (d) Channel cross-sectional area development for a linearly increasing overpressurized segment length between 5 and $5000 \mathrm{~m}$. Note that axes in $(\mathrm{b}-\mathrm{d})$ have different scales.

drainage event at the location in the catchment of Russell Glacier described above. The measured lake elevation is shown by the black curve in Figure $2 \mathrm{a}$ and determines the level of overpressure in the model (i.e. $N_{\text {in }}<0$ ). R-channel growth is estimated for the recorded lake drainage event and for three scenarios in which the lake drainage is extended to two, five and ten times its original duration (Fig. 2a) to determine whether longer lake drainage events have a greater impact on subglacial R-channel growth.

Figure $2 b-d$ show the outputs from the overpressure duration experiment with different domain lengths $l$; in these experiments, I represents the downstream extent of subglacial overpressure during a lake drainage event. Figure $2 b$ shows R-channel growth with $/=500 \mathrm{~m}$. As the overpressure duration is increased, there is little additional channel growth. Even with an overpressure duration ten times that of the case study drainage event ( $>60$ hours), the channel cross-sectional area grows to just $\sim 0.04 \mathrm{~m}^{2}$. This channel growth is limited by the relatively large value of $I$, which prevents a strong hydraulic potential gradient from forming. Figure 2c shows channel growth with a shorter overpressurized segment of $I=200 \mathrm{~m}$. The shorter length over which the water pressure drops has a substantial effect on the growth of R-channels due to the higher pressure gradient driving greater water flux through the channel. Despite this, during the case study lake drainage of 2 hours' duration, channel cross-sectional area grew to only $\sim 0.02 \mathrm{~m}^{2}$. However, if the basal system with $I=200 \mathrm{~m}$ is overpressurized for $>30$ hours, the channels can become large $\left(>10 \mathrm{~m}^{2}\right)$, and at 37 hours the model becomes numerically unstable. In this latter situation, the Nye (1976) equations can no longer be used for determining channel growth.

However, it is unlikely that a section of channel would remain overpressurized over longer time periods; water would spread into a distributed system to stabilize the excess pressure (Hewitt and others, 2012). In the absence of such a process in our model, the length of the overpressurized segment / will nevertheless also not be static during the lake drainage event due to the downstream flux of water as the drainage proceeds. To account for this, the model is run with a value of $/$ that changes over time. Figure $2 \mathrm{~d}$ shows R-channel growth when / is increased linearly from 5 to $5000 \mathrm{~m}$ over the period of drainage. The rate of increase of $I$ is based on the expansion rate of an overpressurized water blister calculated by Tsai and Rice (2010) for the Das and others (2008) lake drainage event. With this expanding region of overpressure, there is negligible R-channel growth if the duration of lake drainage 


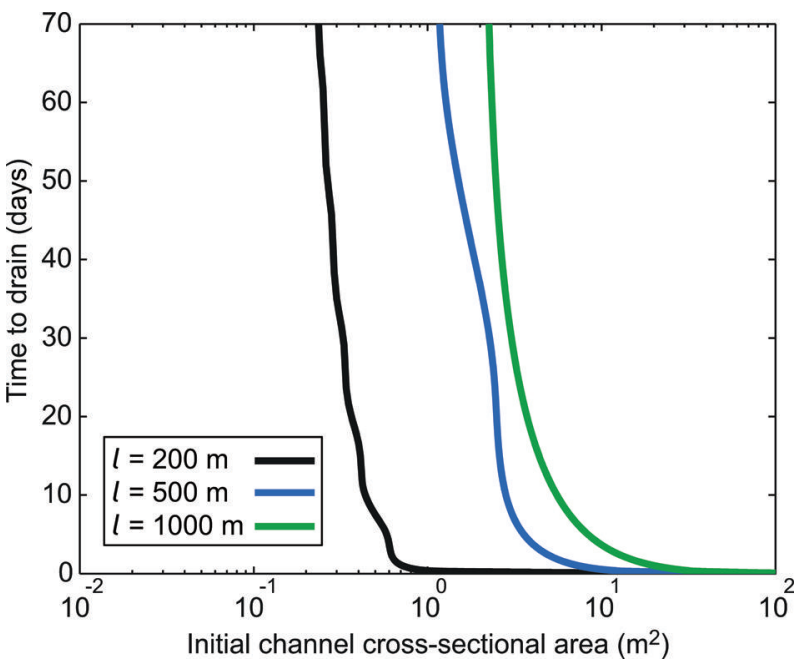

Fig. 3. Time to drain the case study lake determined by channel growth from different initial cross-sectional areas. Outputs are given for static overpressurized segment lengths of 200, 500 and $1000 \mathrm{~m}$.

is extended by five times the recorded drainage time, with the channel cross-sectional area growing to only $\sim 0.06 \mathrm{~m}^{2}$. However, for the long ( 60 hour) drainage duration, there is greater channel growth, resulting in a channel crosssectional area of $1.16 \mathrm{~m}^{2}$.

These experiments indicate that, due to the limited area available for melting and the smaller fluxes (see Eqns (2) and (4)), small channels grow slowly over a timescale of hours, even with a strong pressure gradient. As a result, we conduct an experiment for assessing the growth of channels of varied initial dimensions with fixed values of $I$. We use this to investigate the time it would take to entirely drain the case study lake $\left(7.1 \times 10^{6} \mathrm{~m}^{3}\right)$, using the Gauckler-ManningStrickler channel flow criteria detailed in Eqn (4). The upper boundary $\left(N_{\text {in }} ;\right.$ Fig. 1$)$ pressure condition is prescribed from the measured surface lowering rate of the study lake. Following drainage of the lake, the water lowering rate is not known; therefore, in order to estimate upper bounds on channel growth, we apply a linear decrease in pressure towards overburden over a timescale of 3 hours (this simulates water-level lowering within the connecting moulin). After this period, water pressure at the inlet is set at overburden, and R-channel growth is driven only by the geometric hydraulic potential gradient. Figure 3 shows that for an overpressurized segment of $1000 \mathrm{~m}$ a large initial channel $\left(>20 \mathrm{~m}^{2}\right)$ is necessary to drain the lake water in $<1$ day. For a shorter overpressurized segment of $500 \mathrm{~m}$, an initial channel of $>7.3 \mathrm{~m}^{2}$ is necessary to drain the lake water in $<1$ day. With a static overpressurized segment of $200 \mathrm{~m}$, an initial channel size of $>0.7 \mathrm{~m}^{2}$ is required to drain the lake water in $<1$ day. For channels with initial cross-sectional areas of $<1 \mathrm{~m}^{2}$ and an overpressurized segment of $>500 \mathrm{~m}$, it would take $>70$ days to drain all the water from the supraglacial lake. For an overpressurized segment of $200 \mathrm{~m}$, a channel of $<0.25 \mathrm{~m}^{2}$ initial cross-sectional area takes $>70$ days to drain all the lake water. Our results therefore suggest that a large pre-existing channel is necessary to drain the lake water within 1 day; however, as illustrated earlier, it is unlikely that conditions under kilometer-thick ice would allow growth of a channel of this size either prior to or during lake drainage.

\section{MOULIN EXPERIMENTS}

A large proportion of the water that reaches the bed of the GrIS does so through surface drainage and overtopping of supraglacial lakes that feed into moulins (Selmes and others, 2011; Arnold and others, 2013; Fitzpatrick and others, 2014). Furthermore, rapid lake drainage events form moulins that tap subsequent surface meltwater flux (e.g. Doyle and others, 2013; Tedesco and others, 2013). We therefore examine the growth of R-channels as a result of time-varying water input into a moulin, expressed in our model as changes in moulin effective pressure, in an interior region with kilometer-thick ice. We test four pressure scenarios representing water flux over 30 days into hydrological systems at various stages of growth (Fig. 4a), with initial channel sizes of $0.01,0.1,1$ and $10 \mathrm{~m}^{2}$ (Fig. 4b-e). Our results indicate that even if water pressures are above overburden for up to 12 hours of the day, pressures below $95 \%$ overburden during the remainder of the day prevent channel opening and act to reduce the size of the channel (Fig. 4d-e). Only in the scenario where pressures are continually near or above overburden do the channels become more efficient (Fig. 4b-c).

\section{CHANNEL PERSISTENCE EXPERIMENTS}

Sole and others (2013) suggested that the persistence of efficient low-pressure channels following cessation of surface meltwater input is responsible for enhanced slowdown in winters following warmer higher-velocity summers. Determining under what conditions and how long channels can persist is therefore of interest for understanding the dynamic response of the ice sheet to a warming climate (Shannon and others, 2013). We examine channel closure rates under kilometer-thick ice by prescribing the upstream pressure in our model as overburden $\left(N_{\text {in }}=0\right)$ and the downstream pressure less than overburden $\left(N_{\text {out }}>0\right)$. Our approach extends the work of Chandler and others (2013) who examined closure rates of empty channels under various ice thickness conditions. We instead test closure rates for pressurized channels with cross-sectional areas between 0.1 and $100 \mathrm{~m}^{2}$ with model outlet pressures between $50 \%$ and $99 \%$ of overburden. Owing to the geometric hydraulic potential gradient, the channel will never fully close if filled with water, so instead the critical closure time is determined, defined as the time when the channel cross-sectional area becomes $<1 \mathrm{~cm}^{2}$.

Our results show that as pressures approach overburden (e.g. 99\%), it takes 169 days to close the smallest tested channel and 284 days for a channel of $10 \mathrm{~m}^{2}$ (Fig. 5a). At $95 \%$ of overburden, channels close more rapidly, although it still takes $>10$ days to close a channel of $0.1 \mathrm{~m}^{2}$ (Fig. 5a). Once pressure at the outlet drops to $90 \%$ of overburden, channels can close within 3.5-6.0 days, and at $50 \%$ of overburden, channels close within 7-12 hours (Fig. 5b). As a result, high continual pressures are required to prevent rapid channel closure under kilometer-thick ice. The presence of low-pressure channels, on the other hand, is likely precluded by rapid closure times on the scale of hours to days.

\section{DISCUSSION}

Our R-channel model is used to assess the best-case scenario for channel growth and persistence in interior 

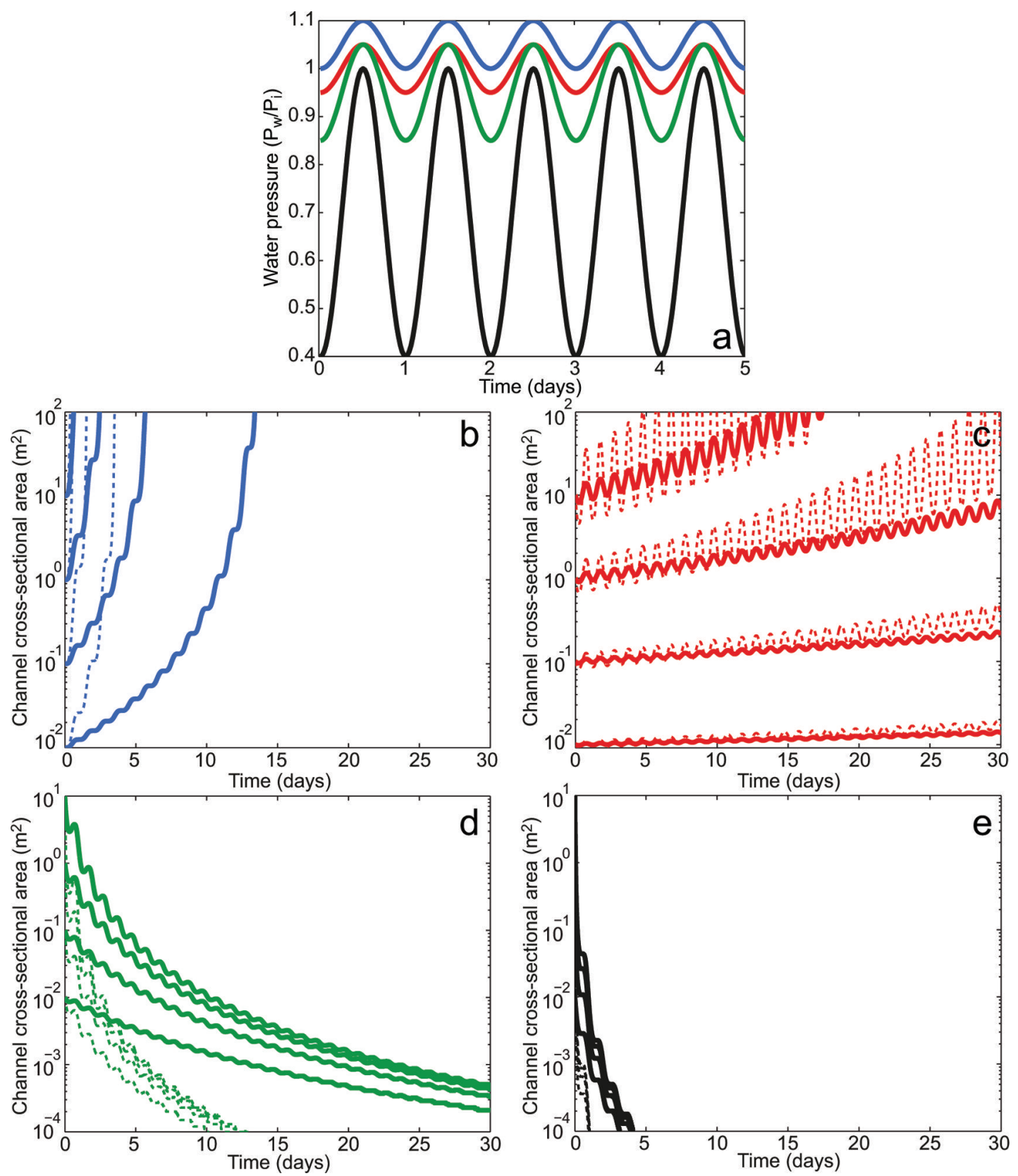

Fig. 4. Channel development driven by simulated moulin water pressure. (a) Diurnally varying water pressure (as a fraction of overburden). (b-e) Channel cross-sectional area development over 30 days for different initial channel cross-sectional areas between 0.01 and $10 \mathrm{~m}^{2}$. Solid curves indicate changes over a static channel segment length of $500 \mathrm{~m}$; dashed curves show changes for a channel segment length of $200 \mathrm{~m}$. Note that axes in (b-e) have different scales. The colors in (b-e) relate to the water pressure driving the model runs, as shown in (a).

regions of the GrIS. To date, research on Greenland supraglacial lake drainage has assumed that a large channel, either pre-existing (Das and others, 2008; Hoffman and others, 2011; Pimentel and Flowers, 2011) or developing during the lake drainage event (Sole and others, 2011; Cowton and others, 2013), is necessary to evacuate the substantial volumes of water that drain from supraglacial lakes to the bed. Our model results indicate that, for the measured lake level in the rapid lake drainage case study, significant channel growth does not occur (Fig. 2). Even when the duration of overpressurization is artificially extended, if there is no established drainage system at the bed (e.g. an initial condition of $S=0.01 \mathrm{~m}^{2}$ ), little channel growth occurs during lake drainage. Our results therefore suggest that the time frame of lake drainage events (often $<3$ hours of overpressure; Das and others, 2008; Doyle and others, 2013; Tedesco and others, 2013) is too short to allow substantial channel growth. Several studies (Das and others, 2008; Hoffman and others, 2011; Pimentel and Flowers, 2011) suggested that a pre-existing channel is necessary to evacuate lake drainage water. In our experiments, if a channel is the only mechanism by which to remove lake drainage water, a pre-existing channel of $>20 \mathrm{~m}^{2}$ cross-sectional area would be required to evacuate lake drainage water within the period of 1 day (Fig. 3). However, as indicated by both our lake drainage (Fig. 2) and moulin drainage (Fig. 4) experiments, the small pressure gradients at our case study site prevent channel growth to such a size.

It has been shown that lakes tend to drain in bands of increasing elevation, with those downstream draining prior to those upstream (e.g. Liang and others, 2012; Fitzpatrick 

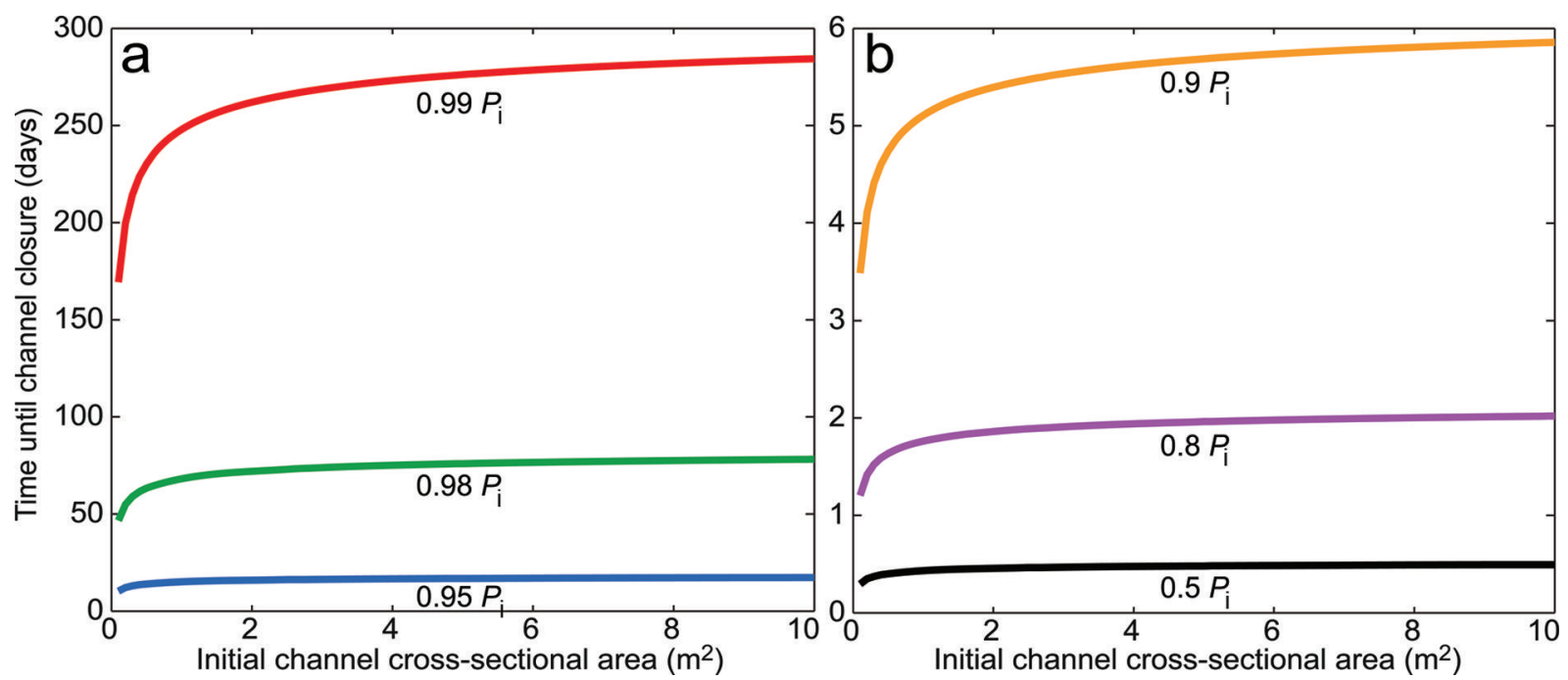

Fig. 5. Time for channels of varying cross-sectional area to close, given a drop in pressure from overburden to below overburden. All calculations are applied to a channel segment length of $500 \mathrm{~m}$.

and others, 2014). This, combined with our model outputs showing limited channel development in regions with shallow surface slopes and small pressure gradients, suggests a large pre-existing channel in the vicinity of interior lake drainage events is unlikely. It is more plausible that water is evacuated from the lake drainage event by a turbulent sheet or linked cavity network instead of a channel alone. Expansion of a turbulent sheet is also suggested by meterscale ice surface uplift observed in the vicinity of the water input point during rapid supraglacial lake drainage (e.g. Das and others, 2008; Doyle and others, 2013). This uplift can be attributed to hydraulic ice-bed separation and suggests that the capacity of the basal drainage system is not sufficient to rapidly remove the large volume of water from lake drainage events. Instead, the drainage system at the bed becomes highly pressurized, with water spreading into a distributed system or turbulent sheet (e.g. Sugiyama and others, 2008). These observations of transient surface uplift support the results of our tests, which suggest that with the short-term but high-volume input associated with interior lake drainage events, efficient channels are unlikely to form.

Longer-term drainage into moulins in high-elevation regions has been argued to have a greater impact on seasonal ice dynamics than rapid lake drainage events (Tedesco and others, 2013). Our moulin experiments indicate that, under kilometer-thick ice, even if water pressure in the moulin is greater than overburden for up to 12 hours during the daily melt cycle, channel growth is limited if pressures are below 95\% overburden during the remainder of the day, and therefore efficient channels cannot persist during the melt season (Fig. 4). Thus, both growing and sustaining channels in interior regions, where shallow surface slopes prevent strong hydraulic potential gradients, require continual high water pressures. Difficulty in maintaining efficient channels in regions of thick ice may explain why drainage into moulins is correlated with increases in local ice velocity, as shown by Tedesco and others (2013). Physical evidence to support the assertion that efficient channels do not form in interior regions comes from tracer experiments at a moulin located $57 \mathrm{~km}$ from the ice-sheet margin on Russell Glacier (Chandler and others, 2013). Tracers injected at this location took $\sim 4$ days to appear at the glacier front, indicating the presence of a distributed rather than efficient drainage system. These data support our model results which suggest that, even with longer-term sustained water inputs into a moulin system, efficient channels are not likely to occur or be sustained in interior regions of the GrlS.

Efficient channel systems near the ice margin have been argued to impact ice velocity following the end of the melt season by remaining at low pressure and drawing water from the surrounding high-pressure distributed drainage network (Burgess and others, 2013; Sole and others, 2013; Tedstone and others, 2013). For kilometer-thick ice, our tests show that a channel of $>1 \mathrm{~m}^{2}$ cross-sectional area can persist for $>250$ days if pressures remain at $99 \%$ of overburden. The hypothesis that efficient channels mediate winter ice velocities requires lower channel pressures to draw water from nearby distributed systems in order to impact ice dynamics. However, with lower pressures at $<90 \%$ of overburden, our model results indicate that the channels shut within several days (Fig. 5). The combination of difficulty in growing efficient channels along with rapid closure of low-pressure channels under thick ice suggests that, in interior regions, reduced winter velocities, as seen by Sole and others (2013) and Tedstone and others (2013), are likely due to a lack of water input to the basal system as opposed to the presence of low-pressure efficient channels. For example, cessation of surface water input at the end of the melt season would cause a local paucity of water along the drainage pathways that would be recharged slowly by the more distant distributed system. If, as our model results suggest, the subglacial hydrological systems in interior regions remain distributed and inefficient throughout the year, water input during the summer melt season could cause sustained flow acceleration. Evidence of net year-onyear ice acceleration at two sites $140 \mathrm{~km}$ from the margin (Doyle and others, 2014) supports this assertion.

Our results suggest that channel growth during lake drainage is not an important aspect of basal hydrological development for interior regions of the GrIS, and seasonal drainage allows growth of significantly smaller channels in interior regions than reported for sites nearer the ice-sheet margin. As a result, we suggest that alternative drainage mechanisms 
(e.g. turbulent sheets in situations of overpressure and linkedcavity systems) should be taken into account when analyzing rapid lake drainage events and interior GrlS hydrological development, as opposed to assuming substantial subglacial channel development, which has been the tendency to date (e.g. Bartholomew and others, 2010, 2012; Cowton and others, 2013; Sole and others, 2013).

\section{CONCLUSIONS}

Our model results give upper bounds on channel growth in interior regions of the GrlS, where ice is thick and surface slopes are low, producing small pressure gradients. These results suggest that $\mathrm{R}$-channels are unlikely to form during the limited duration of overpressure associated with highelevation supraglacial lake drainage events. Continued drainage into moulins may form channels, but only if pressures are maintained above overburden. However, closure rates of channels at pressures below 99\% of overburden suggest that any interior channels are unlikely to become or remain efficient during the melt season, or to significantly draw water from a surrounding distributed system either during or following the melt season. Our results therefore suggest that analogs from thin alpine and Arctic glaciers (Nienow and others, 1998; Burgess and others, 2013; Sole and others, 2013) and from nearer the GrIS margin (Bartholomew and others, 2010; Cowton and others, 2013) are not directly transferable to interior regions of the ice sheet.

\section{ACKNOWLEDGEMENTS}

This project was funded by SKB-Posiva through the Greenland Analogue Project and UK Natural Environment Research Council (NERC) grant NE/G007195/1. C.F.D. was funded by a NERC doctoral scholarship. We thank Rickard Pettersson and Katrin Lindbäck for data, and Ed Bueler for helpful discussions and comments on an early draft of the manuscript. Alison Banwell and an anonymous reviewer are also thanked for constructive comments.

\section{REFERENCES}

Alley RB, Lawson DE, Evenson EB and Larson GJ (2003) Sediment, glaciohydraulic supercooling, and fast glacier flow. Ann. Glaciol., 36, 135-141 (doi: 10.3189/172756403781816121)

Arnold NS, Banwell AF and Willis IC (2013) High-resolution modelling of the seasonal evolution of surface water storage on the Greenland Ice Sheet. Cryos. Discuss., 7(6), 6143-6170 (doi: 10.5194/tcd-7-6143-2013)

Banwell AF, Willis IC and Arnold NS (2013) Modeling subglacial water routing at Paakitsoq, W Greenland. J. Geophys. Res., 118(3), 1282-1295 (doi: 10.1002/jgrf.20093)

Bartholomew I, Nienow P, Mair D, Hubbard A, King MA and Sole A (2010) Seasonal evolution of subglacial drainage and acceleration in a Greenland outlet glacier. Nature Geosci., 3(6), 408-411 (doi: 10.1038/ngeo863)

Bartholomew ID and 6 others (2011) Seasonal variations in Greenland Ice Sheet motion: inland extent and behaviour at higher elevations. Earth Planet. Sci. Lett., 307(3-4), 271-278 (doi: 10.1016/j.epsl.2011.04.014)

Bartholomew I, Nienow P, Sole A, Mair D, Cowton T and King MA (2012) Short-term variability in Greenland Ice Sheet motion forced by time-varying meltwater drainage: implications for the relationship between subglacial drainage system behavior and ice velocity. J. Geophys. Res., 117(F3), F03002 (doi: 10.1029/ 2011JF002220)
Burgess EW, Larsen CF and Forster RR (2013) Summer melt regulates winter glacier flow speeds throughout Alaska. Geophys. Res. Lett., 40(23), 6160-6164 (doi: 10.1002/2013GL058228)

Catania GA and Neumann TA (2010) Persistent englacial drainage features in the Greenland Ice Sheet. Geophys. Res. Lett., 37(2), L02501 (doi: 10.1029/2009GL041108)

Catania GA, Neumann TA and Price SF (2008) Characterizing englacial drainage in the ablation zone of the Greenland ice sheet. J. Glaciol., 54(187), 567-578 (doi: 10.3189/ 002214308786570854)

Chandler DM and 11 others (2013) Evolution of the subglacial drainage system beneath the Greenland Ice Sheet revealed by tracers. Nature Geosci., 6(3), 195-198 (doi: 10.1038/ngeo1737)

Cowton T and 7 others (2013) Evolution of drainage system morphology at a land-terminating Greenlandic outlet glacier. J. Geophys. Res., 118(F1), 29-41 (doi: 10.1029/2012JF002540)

Cuffey KM and Paterson WSB (2010) The physics of glaciers, 4th edn. Butterworth-Heinemann, Oxford

Das SB and 6 others (2008) Fracture propagation to the base of the Greenland Ice Sheet during supraglacial lake drainage. Science, 320(5877), 778-781 (doi: 10.1126/science.1153360)

Doyle SH and 9 others (2013) Ice tectonic deformation during the rapid in situ drainage of a supraglacial lake on the Greenland Ice Sheet. Cryosphere, 7(1), 129-140 (doi: 10.5194/tc-7-129-2013)

Doyle SH and 6 others (2014) Persistent flow acceleration within the interior of the Greenland ice sheet. Geophys. Res. Lett., 41(3), 899-905 (doi: 10.1002/2013GL058933)

Fitzpatrick AAW and 9 others (2014) A decade (2002-2012) of supraglacial lake volume estimates across Russell Glacier, West Greenland. Cryosphere, 8(1), 107-121 (doi: 10.5194/ tc-8-107-2014)

Flowers GE and Clarke GKC (2002) A multicomponent coupled model of glacier hydrology: 1 . Theory and synthetic examples. J. Geophys. Res., 107(B11), 2287 (doi: 10.1029/2001JB001122)

Fowler AC (1999) Breaking the seal at Grímsvötn, Iceland. J. Glaciol., 45(151), 506-516

Hewitt IJ (2011) Modelling distributed and channelized subglacial drainage: the spacing of channels. J. Glaciol., 57(202), 302-314 (doi: 10.3189/002214311796405951)

Hewitt IJ, Schoof C and Werder MA (2012) Flotation and free surface flow in a model for subglacial drainage. Part 2. Channel flow. J. Fluid Mech., 702, 157-187 (doi: 10.1017/jfm.2012.166)

Hoffman MJ, Catania GA, Neumann TA, Andrews LC and Rumrill JA (2011) Links between acceleration, melting, and supraglacial lake drainage of the western Greenland Ice Sheet. J. Geophys. Res., 116(F4), F04035 (doi: 10.1029/2010JF001934)

Kingslake J and Ng F (2013) Modelling the coupling of flood discharge with glacier flow during jökulhlaups. Ann. Glaciol., 54(63 Pt 1), 25-31 (doi: 10.3189/2013AoG63A331)

Liang Y-L and 7 others (2012) A decadal investigation of supraglacial lakes in West Greenland using a fully automatic detection and tracking algorithm. Remote Sens. Environ., 123, 127-138 (doi: 10.1016/j.rse.2012.03.020)

Lindbäck K and 8 others (2014) High-resolution ice thickness and bed topography of a land-terminating section of the Greenland Ice Sheet. Earth Syst. Sci. Data Discuss., 7(1), 129-148 (doi: 10.5194/essdd-7-129-2014)

Meierbachtol T, Harper J and Humphrey N (2013) Basal drainage system response to increasing surface melt on the Greenland Ice Sheet. Science, 341(6147), 777-779 (doi: 10.1126/ science.1235905)

Nienow P, Sharp M and Willis I (1998) Seasonal changes in the morphology of the subglacial drainage system, Haut Glacier d'Arolla, Switzerland. Earth Surf. Process. Landf., 23(9), 825-843 (doi: 10.1002/(SICI)1096-9837(199809)23:9<825:: AID-ESP893>3.0.CO;2-2)

Nye JF (1976) Water flow in glaciers: jökulhlaups, tunnels and veins. J. Glaciol., 17(76), 181-207

Pimentel S and Flowers GE (2011) A numerical study of hydrologically driven glacier dynamics and subglacial flooding. Proc. 
R. Soc. London, Ser. A, 467(2126), 537-558 (doi: 10.1098/rspa. 2010.0211)

Röthlisberger H (1972) Water pressure in intra- and subglacial channels. J. Glaciol., 11(62), 177-203

Schoof C (2010) Ice-sheet acceleration driven by melt supply variability. Nature, 468(7325), 803-806 (doi: 10.1038/ nature09618)

Schoof C, Hewitt IJ and Werder MA (2012) Flotation and free surface flow in a model for subglacial drainage. Part 1. Distributed drainage. J. Fluid Mech., 702, 126-156 (doi: 10.1017/jfm.2012.165)

Selmes N, Murray T and James TD (2011) Fast draining lakes on the Greenland Ice Sheet. Geophys. Res. Lett., 38(15), L15501 (doi: 10.1029/2011GL047872)

Shannon SR and 18 others (2013) Enhanced basal lubrication and the contribution of the Greenland ice sheet to future sea-level rise. Proc. Natl Acad. Sci., 110(35), 14 156-14161 (doi: 10.1073/pnas.1212647110)

Shepherd A, Hubbard A, Nienow P, McMillan M and Joughin I (2009) Greenland ice sheet motion coupled with daily melting in late summer. Geophys. Res. Lett., 36(1), L01501 (doi: 10.1029/2008GL035758)

Shreve RL (1972) Movement of water in glaciers. J. Glaciol., 11(62), 205-214
Sole AJ and 6 others (2011) Seasonal speedup of a Greenland marine-terminating outlet glacier forced by surface meltinduced changes in subglacial hydrology. J. Geophys. Res., 116(F3), F03014 (doi: 10.1029/2010JF001948)

Sole A and 6 others (2013) Winter motion mediates dynamic response of the Greenland Ice Sheet to warmer summers. Geophys. Res. Lett., 40(15), 3940-3944 (doi: 10.1002/ grl.50764)

Sugiyama S, Bauder A, Huss $M$, Riesen $P$ and Funk $M$ (2008) Triggering and drainage mechanisms of the 2004 glacier-dammed lake outburst in Gornergletscher, Switzerland. J. Geophys. Res., 113(F4), F04019 (doi: 10.1029/ 2007JF000920)

Tedesco M, Willis IC, Hoffman MJ, Banwell AF, Alexander P and Arnold NS (2013) Ice dynamic response to two modes of surface lake drainage on the Greenland ice sheet. Environ. Res. Lett., 8(3), 034007 (doi: 10.1088/1748-9326/8/3/034007)

Tedstone AJ and 6 others (2013) Greenland ice sheet motion insensitive to exceptional meltwater forcing. Proc. Natl Acad. Sci., 110(49), 19719-19724 (doi: 10.1073/pnas.1315843110)

Tsai VC and Rice JR (2010) A model for turbulent hydraulic fracture and application to crack propagation at glacier beds. J. Geophys. Res., 115(F3), F03007 (doi: 10.1029/ 2009JF001474)

MS received 12 May 2014 and accepted in revised form 9 August 2014 